\title{
Synthesis of 2-substituted pyridines from pyridine $N$-oxides
}

\author{
Chunli Liu, ${ }^{a}$ Jiang Luo, ${ }^{b}$ Lingli Xu, ${ }^{b}$ and Zhibao Huo ${ }^{* b}$ \\ ${ }^{a}$ School of Chemistry and Material Science, Guizhou Normal University, \\ 116 Baoshan Bei Lu, Guiyang 550001, China \\ ${ }^{b}$ School of Environmental Science and Engineering, Shanghai Jiao Tong University, \\ 800 Dongchuan Road, Shanghai 200240, China \\ E-mail: $\underline{\text { hzb410@sjtu.edu.cn }}$
}

\begin{abstract}
The synthesis of substituted pyridines has drawn the attention of many chemists due to their importance as building blocks for biologically active compounds and materials. This mini-review focuses on recent developments relating to the synthesis of substituted pyridines from pyridine $N$-oxides, along with their interesting mechanism aspects. New developments including alkenylation, alkynylation, alkylation, arylation, amination and cyanation are discussed.
\end{abstract}

Keywords: Substituted pyridines, pyridine $N$-oxides

\section{Contents}

1. Introduction

2. Transition Metal-catalyzed Alkenylation

3. Palladium-catalyzed Arylation

4. Amination

5. Cyanation

6. Transition-metal Free Regiospecific Alkylation

7. Transition-metal Free Alkynylation

8. Palladium-catalyzed Direct (Hetero)arylation

9. Conclusions

10. Acknowledgements

References 


\section{Introduction}

Substituted pyridines are an important class of compounds in organic synthesis. ${ }^{1}$ The structural framework of substituted pyridines is often seen in natural products, compounds possessing important biological activities, and functional materials. ${ }^{2}$ Substituted pyridines are usually prepared starting from halo- or metallated pyridyl compounds. However, this method is commonly accompanied with problems and the formation of by-products.

Pyridine $N$-oxides ${ }^{3}$ are very useful synthetic intermediates in the field of heterocyclic chemistry, since they are much more reactive towards both electrophilic and nucleophilic reagents than the heterocycles from which they are derived. ${ }^{4}$ Reactions of pyridine $N$-oxides is one of the most useful synthetic methods for the formation of various substituted pyridines and their derivatives. Over recent decades, pyridine $N$-oxides have drawn the attention of numerous research groups, and the number of new synthetic methodologies and modifications of traditional procedures has grown markedly, which has been reflected in the number of research publications in the literature. This mini-review focuses on recent developments relating to the synthesis of substituted pyridines from pyridine $N$-oxides along with their interesting mechanism aspects. Accordingly, we discuss only the most essential reactions here and summarize the recent contributions reported after 2002.

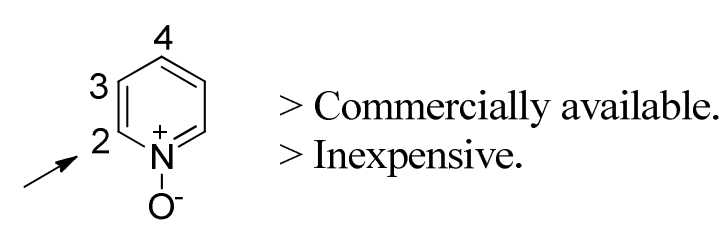

Figure 1. Pyridine $N$-oxide.

\section{Transition Metal-catalyzed Alkenylation}

Recently, Chang et al. reported highly promising oxidative protocol for the selective alkenylation of pyridine $\mathrm{N}$-oxides $\mathbf{1}$ using olefins $\mathbf{2}$ relying on the palladium mediated $\mathrm{C}-\mathrm{H}$ bond activation strategy (Scheme 1). ${ }^{5}$ Various alkenylated pyridine $N$-oxides 3 were obtained in good to high yields. The resultant alkenylated pyridine $N$-oxides (e.g., 3a) were readily deoxygenated to give 2-alkenylpyridines $\mathbf{4}$, making the present alkenylation route a highly attractive alternative for the 2-functionalization of pyridine derivatives. In addition, $\mathrm{Cui}, \mathrm{Wu}$ and co-workers revealed for the first time in Pd-catalyzed alkenylation of quinoline- and isoquinoline- $N$-oxides via $\mathrm{C}-\mathrm{H}$ activation under external-oxidant-free conditions (Scheme 2). ${ }^{6}$ 

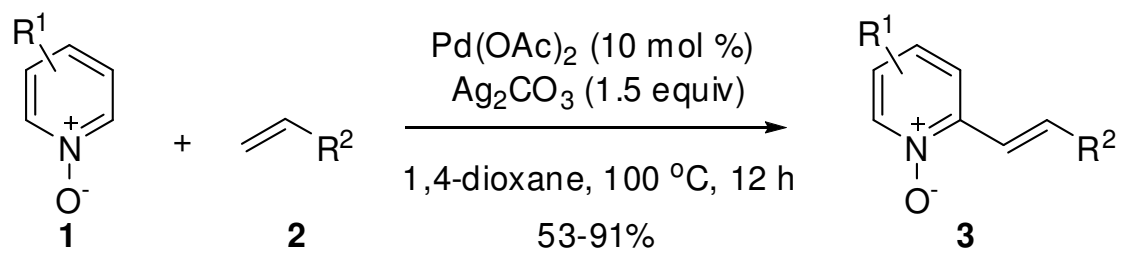

$\mathrm{R}^{1}=2-\mathrm{Ph}, 3-\mathrm{Ph}, 4-\mathrm{Ph}$

$\mathrm{R}^{2}=\mathrm{CONMe}_{2}, \mathrm{COMe},{ }^{t} \mathrm{Bu}, \mathrm{Ph}, \mathrm{CO}_{2}{ }^{t} \mathrm{Bu}, \mathrm{PO}(\mathrm{OEt})_{2}$<smiles>CCOC(=O)C=Cc1cccc[n+]1[O-]</smiles>

$3 a$

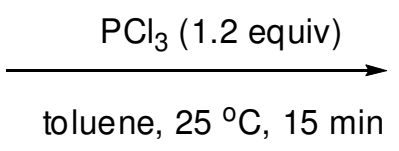

$92 \%$

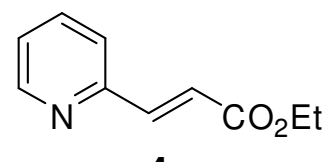

4

\section{Scheme 1}

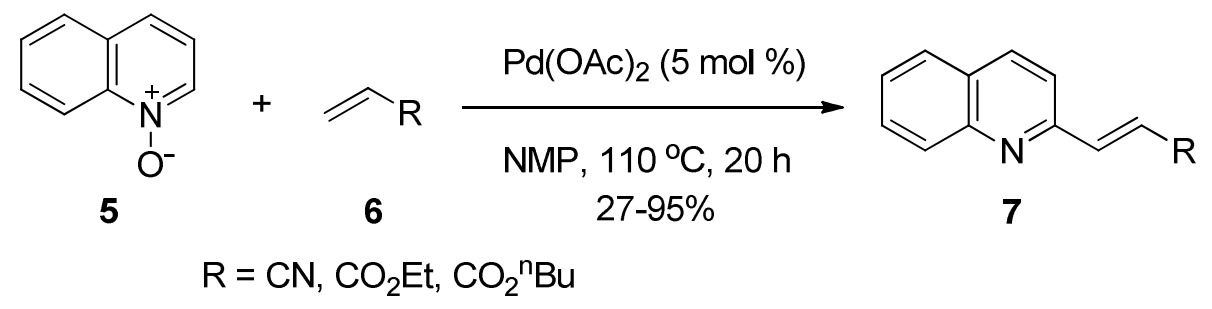

\section{Scheme 2}

Hiyama et al. reported nickel-catalyzed activation of $\mathrm{C}(2)$ - $\mathrm{H}$ bonds of pyridine $N$-oxides $\mathbf{1}$ under mild conditions followed by regio- and stereoselective insertion of alkynes $\mathbf{8}$ to afford $(E)$ 2-alkenylpyridine $\mathrm{N}$-oxides 9 in modest to good yields (Scheme 3). ${ }^{7}$ The resulting adducts were readily deoxygenated to give various substituted pyridines $\mathbf{1 0}$. 


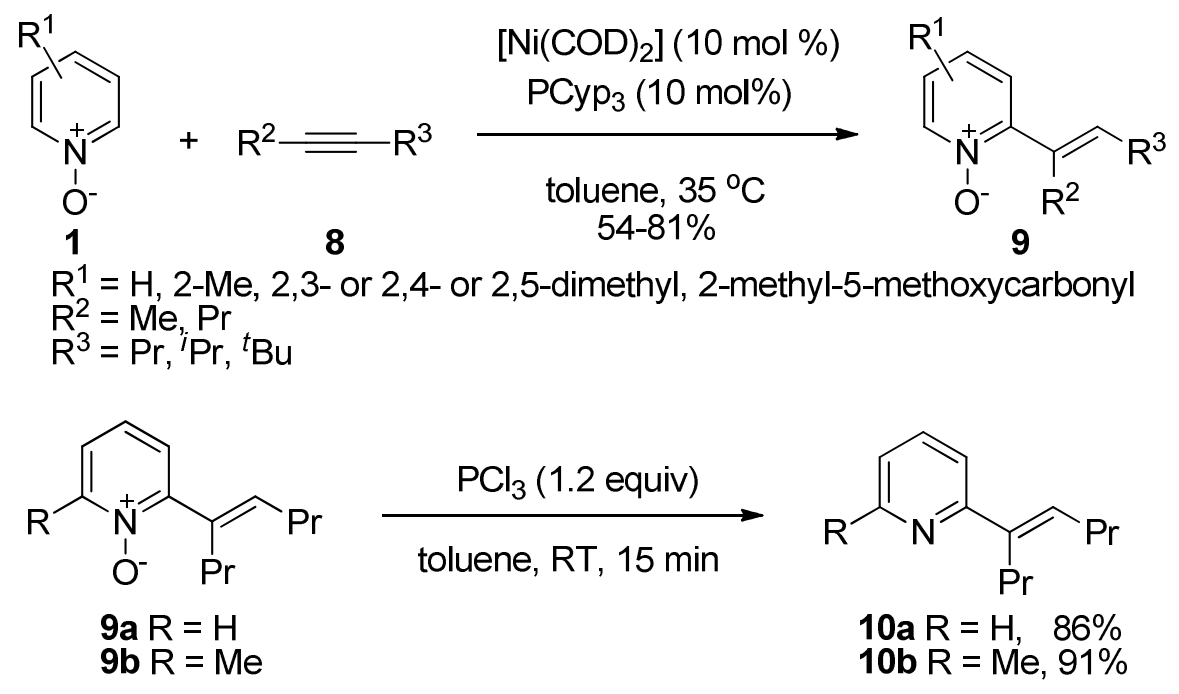

\section{Scheme 3}

A plausible mechanism for the nickel-catalyzed alkenylation of pyridine $\mathrm{N}$-oxides is shown in Scheme 4. Alkyne-coordinated nickel (0) species A underwent oxidative addition to the $\mathrm{C}_{2}-\mathrm{H}$ bond, giving the pyridyl(hydride)- nickel species B. Hydronickelation in a cis fashion then provided the alkenyl(pyridyl)nickel intermediate $\mathbf{C}$. Coordination of the alkyne such that the steric repulsion between the bulkier $\mathrm{R}^{3}$ and the pyridyl group in $\mathbf{B}$ was avoided would be responsible for the observed regioselectivities. Reductive elimination followed by coordination of an alkyne afforded 2-alkenylpyridine- $N$-oxide $\mathbf{9}$ and regenerated the nickel (0) species A. The $\mathrm{N}$-oxide moiety played an important role in directing the metal catalyst to the proximal $\mathrm{C}_{2}-\mathrm{H}$ bond and/or making the $\mathrm{C}-\mathrm{H}$ bond acidic enough to undergo the oxidative addition to nickel (0).

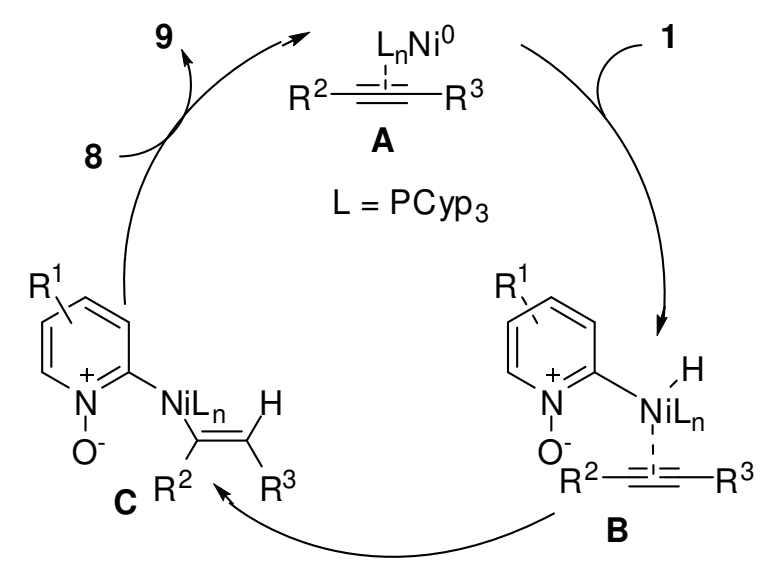

\section{Scheme 4}




\section{Palladium-Catalyzed Arylation}

Fagnou et al. reported palladium-catalyzed direct arylation reactions of pyridine $\mathrm{N}$-oxides (azine and azole $N$-oxides ${ }^{8,9,10}$ ) occur in excellent yield with complete selectivity for the 2-position with a wide range of aryl bromides 11. The resulting 2-arylpyridine $\mathrm{N}$-oxides could be easily reduced to the free pyridine 12 via palladium-catalyzed hydrogenolysis (Scheme 5). ${ }^{11}$

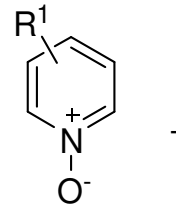

1

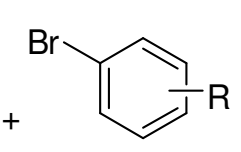

11
1) $\mathrm{Pd}(\mathrm{OAc})_{2}, \mathrm{P}^{t} \mathrm{Bu}_{3}-\mathrm{HBF}_{4}$ $\mathrm{K}_{2} \mathrm{CO}_{3}$, PhMe, $110^{\circ} \mathrm{C}$

2) $\mathrm{Pd} / \mathrm{C}, \mathrm{HCOONH}_{4}$ $\mathrm{MeOH}, \mathrm{rt}$ 45-97\%<smiles>[R][R]1ccc(-c2ccc[R]n2)cc1</smiles>

12

$\mathrm{R}=2$ or 4-Me, 3,5-dimethyl, 3 or $4-\mathrm{MeO}, 4-\mathrm{CF}_{3}, 4-\mathrm{CO}_{2} \mathrm{Me}$

$\mathrm{R}^{1}=\mathrm{H}, 4-$ methoxy, 4-nitro

\section{Scheme 5}

A recent report by the same author revealed that lower yields were encountered with substrates bearing methyl substituents adjacent to the $N$-oxide moiety, they developed site selective arylation reactions of both $\mathrm{sp}^{2}$ and benzylic $\mathrm{sp}^{3}$ sites on pyridine $N$-oxide substrates and illustrate that reactivity could be performed both divergently and sequentially (Scheme 6). ${ }^{12,13}$ Furthermore, the $N$-oxide moiety could be used to introduce a wide range of other functional groups or could easily be deoxygenated under mild conditions.<smiles>[R]c1ccc[n+]([O-])c1[Tl]</smiles>$$
\mathrm{R}^{1}=\mathrm{H}, 5-\mathrm{CN}, 4-\mathrm{Me}
$$$$
\mathrm{R}^{2}=\text { Me, 2-tolyl, Et }
$$$$
\mathrm{R}^{3}=4-\mathrm{MeO}, 3,5-\text { dimethyl, 3,5-dimethoxy, 4-Me }
$$

1) $\mathrm{Pd}(\mathrm{OAc})_{2}, \mathrm{P}^{t} \mathrm{Bu}_{3}-\mathrm{HBF}_{4}$ $\mathrm{K}_{2} \mathrm{CO}_{3}, \mathrm{PhMe}, 110^{\circ} \mathrm{C}$

2) $\mathrm{Pd} / \mathrm{C}, \mathrm{HCOONH}_{4}$ $\mathrm{MeOH}, \mathrm{rt}$ $59-73 \%$<smiles></smiles>

14

\section{Scheme 6}

Direct arylation of pyridine $\mathrm{N}$-oxides with aryl triflates can also be obtained. Fagnou et al. reported palladium-catalyzed direct arylation of pyridine $N$-oxides using aryl triflates to afford the corresponding 2-aryl pyridine $N$-oxides (Scheme 7). ${ }^{14}$ Differentially diarylated products could be obtained by carrying out tht arylation reactions in sequence as shown in Scheme 8 . Pyridine $\mathrm{N}$-oxide was arylated with $p$-tolyl trifluoromethanesulfonate in $89 \%$ yield. This product 
could then be resubmitted to arylation conditions with 4-methoxyphenyl trifluoromethanesulfonate under the more active conditions to generate the differentially diarylated compound $\mathbf{2 0}$ in $84 \%$ yield. Conditions A, which employed aryl triflates, resulted in not only higher yield than the previously reported conditions $\mathbf{B}$ (with aryl bromides) but also required less equivalents of intermediate 19. Therefore, it could be advantageous to employ aryl triflates when low yields were obtained with aryl bromides.<smiles>[1H]c1cc[R]c[n+]1[O-]</smiles>

1<smiles>Brc1ccccc1</smiles>

15

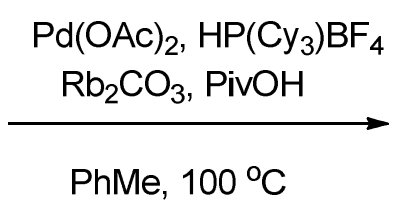

PhMe, $100^{\circ} \mathrm{C}$<smiles>[R]1ccnc(-c2ccccc2)c1</smiles>

16

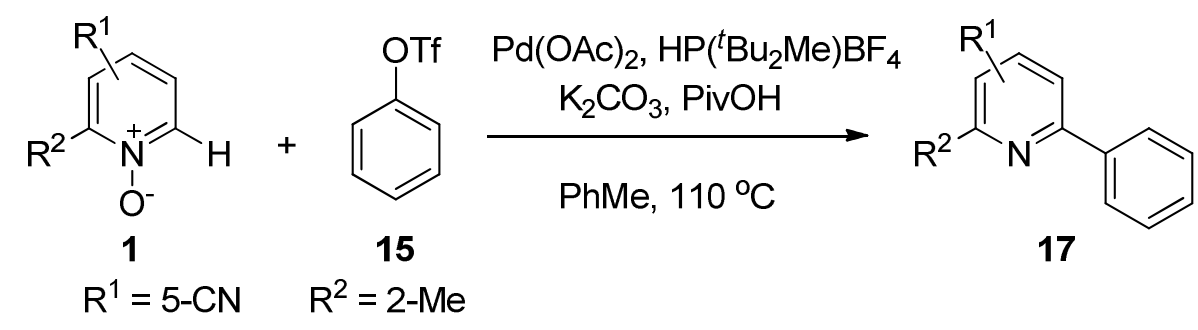

\section{Scheme 7}<smiles>[O-][n+]1ccccc1</smiles>

1a<smiles>Cc1ccc(O)cc1</smiles>
$\mathrm{Pd}(\mathrm{OAc})_{2}, \mathrm{HP}\left(\mathrm{Cy}_{3}\right) \mathrm{BF}_{4}$

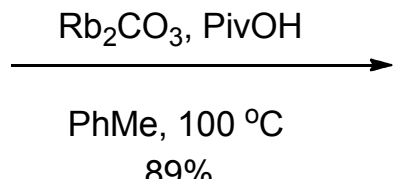<smiles>Cc1ccc(-c2cccc[n+]2[O-])cc1</smiles><smiles>[X]c1ccc(OC)cc1</smiles>
$89 \%$ 19<smiles>COc1ccc(-c2cccc(-c3ccc(C)cc3)n2)cc1</smiles>

\begin{tabular}{|c|c|c|}
\hline Conditions & $X$ & Yield \\
\hline 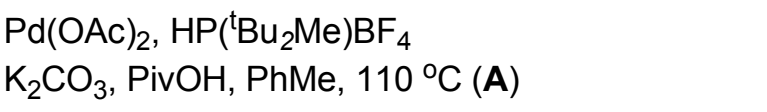 & OTf & $84 \%$ \\
\hline $\begin{array}{l}\text { 1) } \mathrm{Pd}(\mathrm{OAc})_{2}, \mathrm{P}^{t} \mathrm{Bu}_{3}-\mathrm{HBF}_{4}, \mathrm{~K}_{2} \mathrm{CO}_{3}, \mathrm{PhMe}, 110^{\circ} \mathrm{C} \\
\text { 2) } \mathrm{Pd} / \mathrm{C}, \mathrm{HCOONH}{ }_{4}, \mathrm{MeOH}, \mathrm{rt}(\mathrm{B})\end{array}$ & $\mathrm{Br}$ & $50 \%$ ref 11 \\
\hline
\end{tabular}

\section{Scheme 8}




\section{Amination}

Yin et al. developed a general and efficient method to convert pyridine $\mathrm{N}$-oxides to 2aminopyridines $\mathbf{2 3}$ in a one-pot process in high yields and high regioselectivity. The process used commercially available reagents $t-\mathrm{BuNH}_{2}$ and $\mathrm{Ts}_{2} \mathrm{O}$ and showed good functional group compatibility (Scheme 9). ${ }^{15}$ The use of $t-\mathrm{BuNH}_{2}$ was critical for shutting down side reactions such as dimerization and tosylation of the product as well as suppressing the reaction between the amine and the activating reagent $\mathrm{Ts}_{2} \mathrm{O}$. TFA treatment of the crude reaction mixture effectively removed the $t$-Bu group.

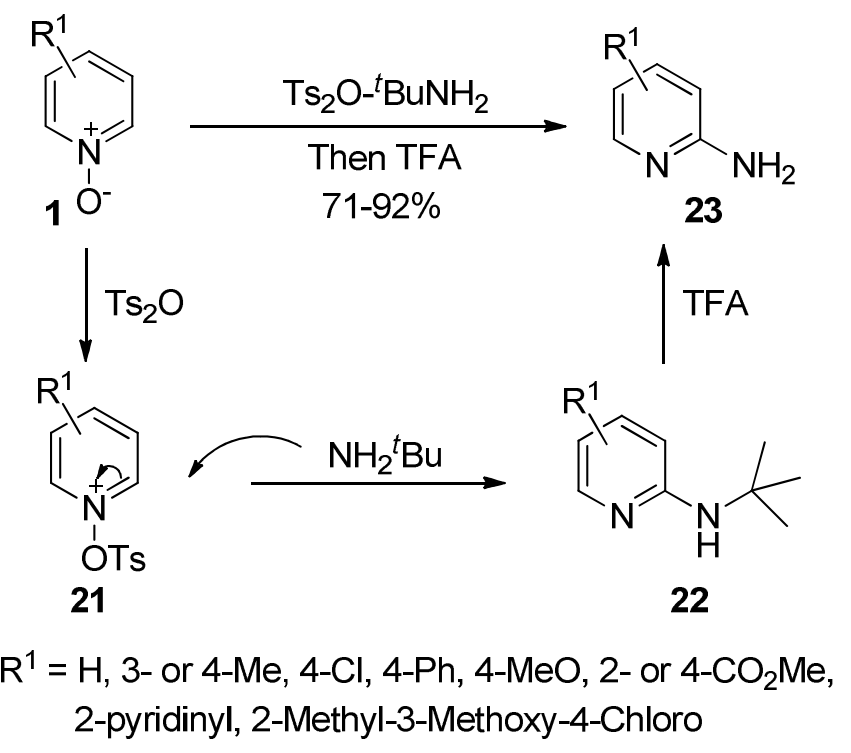

\section{Scheme 9}

Londregan et al. reported a general and facile one-pot amination procedure for the synthesis of 2-aminopyridines from the corresponding pyridine $\mathrm{N}$-oxides as a mild altermative to $\mathrm{S}_{\mathrm{N}} \mathrm{Ar}$ chemistry. The authors found that the phosphonium salt PyBroP (bromotripyrrolidinophosphonium hexafluorophosphate) functioned as a general and mild $\mathrm{N}$-oxide activator for the regioselective addition of amine nucleophiles. In this reaction, unhinderedaliphatic amines participated most effectively in the transformation, but aminations using heterocycles, such as imidazoles and pyrazoles, unexpectedly proceeded (Scheme 10). ${ }^{16}$ The mechanism of the reaction is shown in Scheme 11. The reaction proceeded via the activated pyridine complex 24. Subsequent basic rearomatization 25 afforded the desired 2-aminopyridine 23 and phosphoryltripyrrolidine 26, the only significant organic byproduct of the reaction. Recently, the same group also found that reactions could be expanded into broader classes of nucleophiles (such as phenol, sulfonamide, malonate, pyridone, thiol) after minimal reaction 
optimization of original amination procedure. The presented reactions represented a very large and varied set of putative nucleophiles and $\mathrm{N}$-oxides. ${ }^{17}$

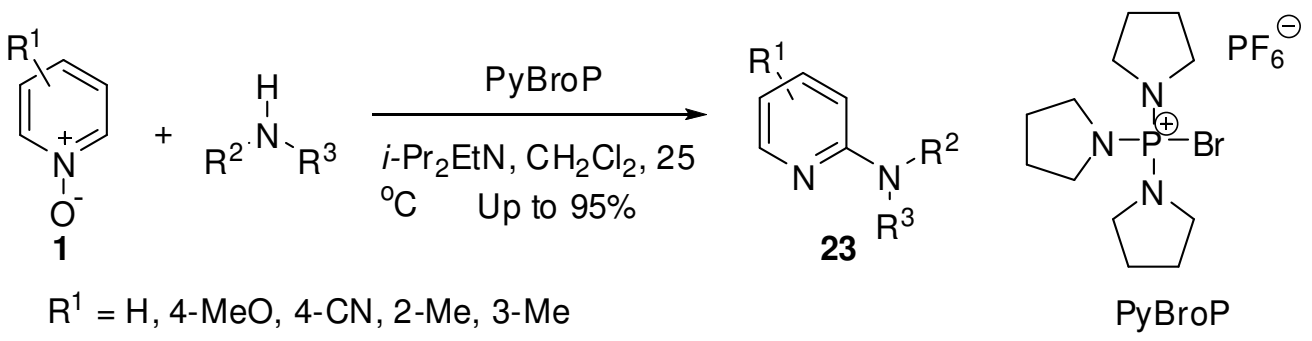

\section{Scheme 10}

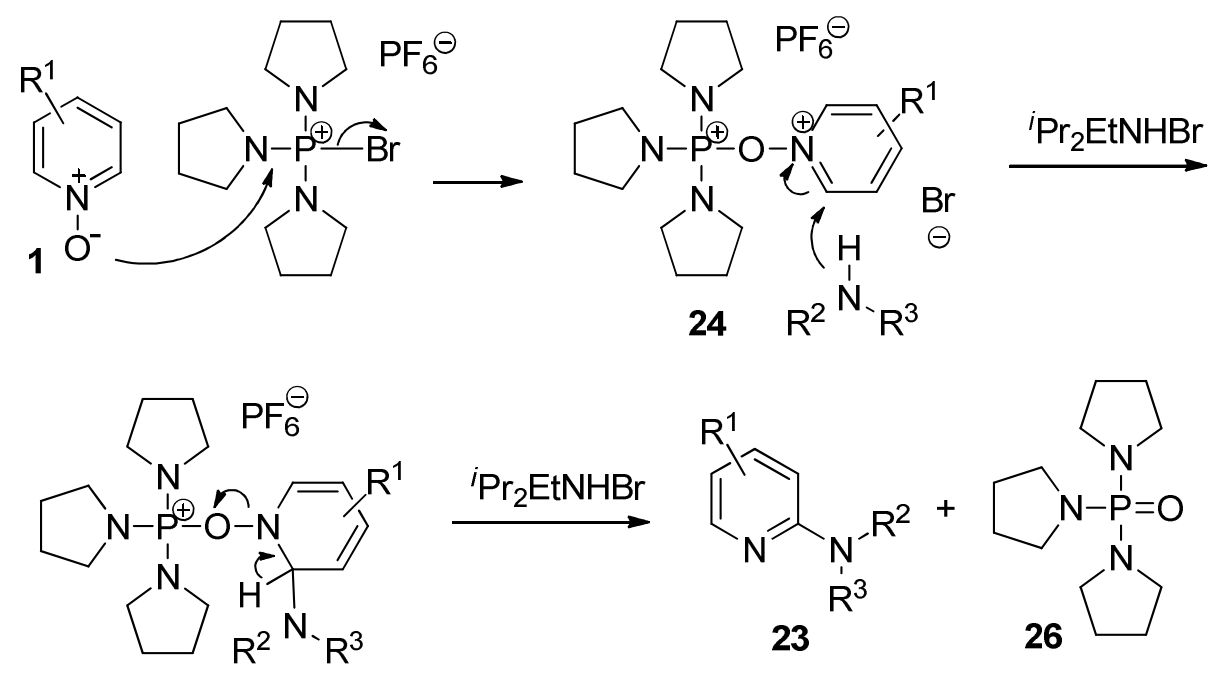

25

\section{Scheme 11}

A one-pot method for the generation of imidoyl chlorides and their subsequent in situ reaction with pyridine $N$-oxides was developed by Manley and Bilodeau (Scheme 12). ${ }^{18}$ The imidoyl chlorides were formed from the reaction of secondary amides with a stoichiometric amount of oxalyl chloride and 2,6-lutidine in $\mathrm{CH}_{2} \mathrm{Cl}_{2}$ at $0{ }^{\circ} \mathrm{C}$. Upon warming of the reaction mixture to room temperature in the presence of pyridine $\mathrm{N}$-oxides, a rapid conversion to 2aminopyridine amides $\mathbf{2 8}$ was observed in moderate to excellent isolated yields. 
<smiles>[R]C(=O)N[12B]</smiles>

27
1) oxalyl chloride, 2,6lutidine, $\mathrm{CH}_{2} \mathrm{Cl}_{2}, 0^{\circ} \mathrm{C}$

2)

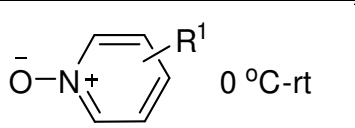

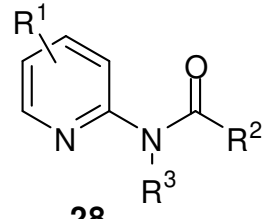

28

$\mathrm{R}^{1}=\mathrm{H}, 4-\mathrm{Me}, 4-\mathrm{Ph}, 4-\mathrm{BnO}, 3-\mathrm{Me}, 2-\mathrm{Me}$

\section{Scheme 12}

Keith reported a convenient one-step procedure for the conversion of pyridine $N$-oxides to 2 imidazolopyridines $\mathbf{3 0}$ in fair to excellent yield through the action of sulfuryl diimadazole at elevated temperatures. ${ }^{19}$ A possible mechanism for the activation and substitution of pyridine $N$ oxides with potential side reactions is shown in Scheme 13.<smiles></smiles>

1<smiles>O=S(=O)(n1ccnc1)n1ccnc1</smiles>

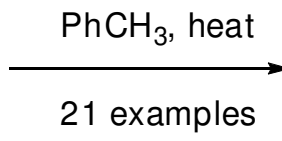

21 examples

29<smiles>[R17]1ccnc(-n2ccnc2)c1</smiles>

$\mathrm{R}^{1}=\mathrm{H}, 4-\mathrm{Ph}, 3-$ or 4-CN, 2- or 3- or 4-MeO, 2-Me, 3,5-dimethyl, 2-pyridinyl, 3-I, 3,4-dimethyl

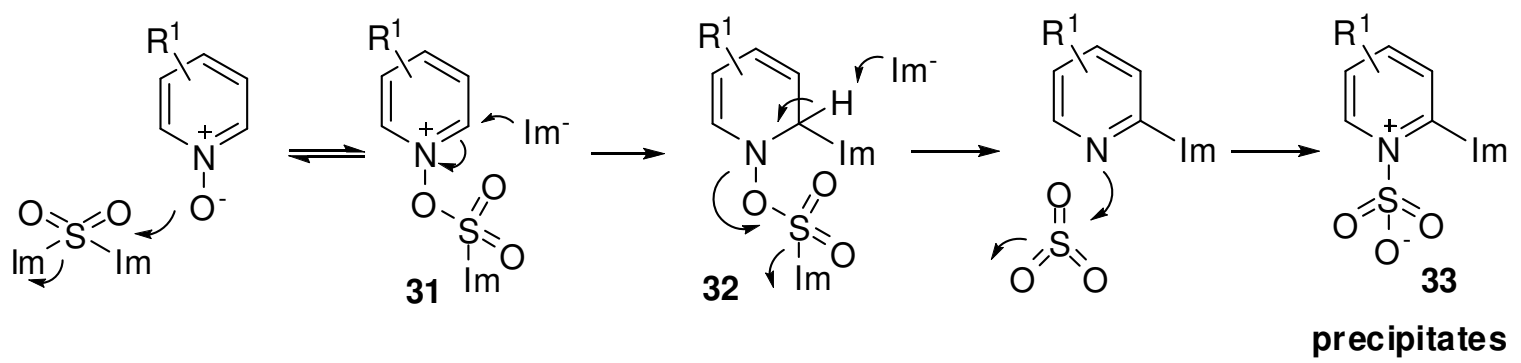

\section{Scheme 13}

Recently, same researcher also developed a method for the deoxygenative coupling of pyridine $\mathrm{N}$-oxides with azoles through the use of preformed tosylazole reagents. The 
methodology allowed for the introduction of 1,2,4- and 1,2,3-triazoles, imidazole, and electrondeficient pyrazoles on pyridine (Scheme 14$){ }^{20 .}$

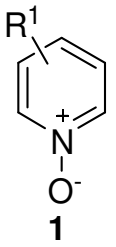

1

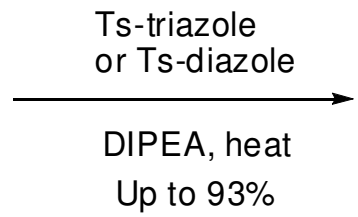

DIPEA: diisopropylethylamine

$\mathrm{R}^{1}=\mathrm{H}$, 4-Ph, 3,5-dimethyl, 2-Me, 3- or 4-MeO, 4- $\mathrm{NMe}_{2}$

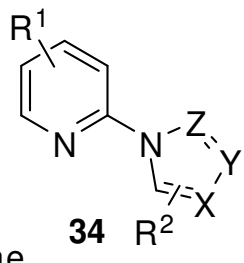

$34 \mathrm{R}^{2}$

\section{Scheme 14}

\section{Cyanation}

Recently, Yamamoto et al. reported a convenient method for the direct synthesis of 2-cyanoisonicotinamide $\mathbf{3 5}$ from isonicotinic acid $\mathrm{N}$-oxide using zinc cyanide as a cyanation reagent (Scheme 15). ${ }^{21}$ The reaction mechanism is shown in Scheme 16.

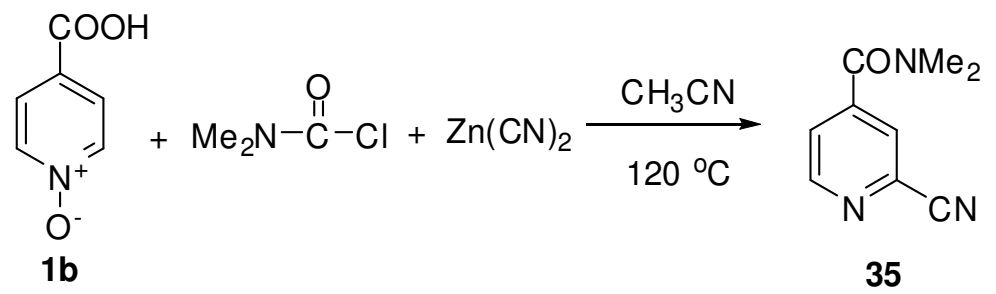

\section{Scheme 15}




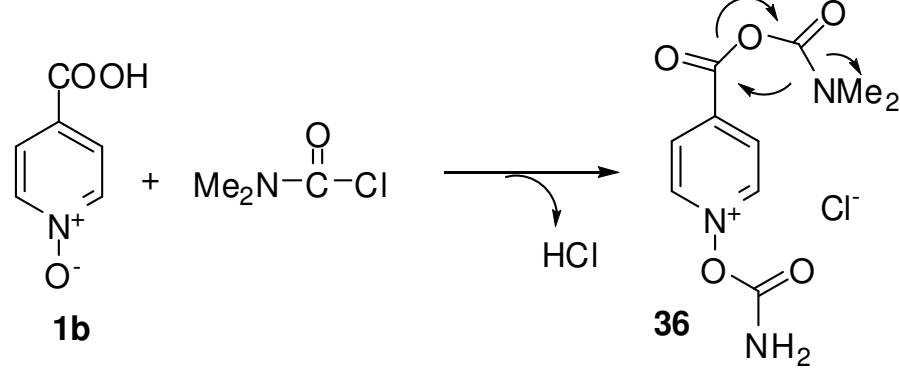

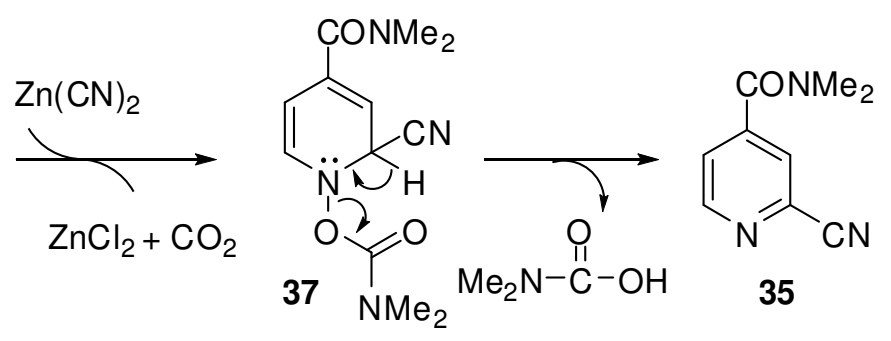

\section{Scheme 16}

Furthermore, this strategy could be applied to the synthesis of FYX-051-TsOH (40), a xanthine oxidoreductase inhibitor (Scheme 17). Additionally, they reported a reaction of 4amidopyridine $\mathrm{N}$-oxide with dimethylcarbamoyl chloride and potassium cyanide in $\mathrm{CH}_{3} \mathrm{CN}$ at $120{ }^{\circ} \mathrm{C}$ and gave the corresponding 2-cyano-4-amidopyridine 41 in a good yield (Scheme 18). ${ }^{22}$

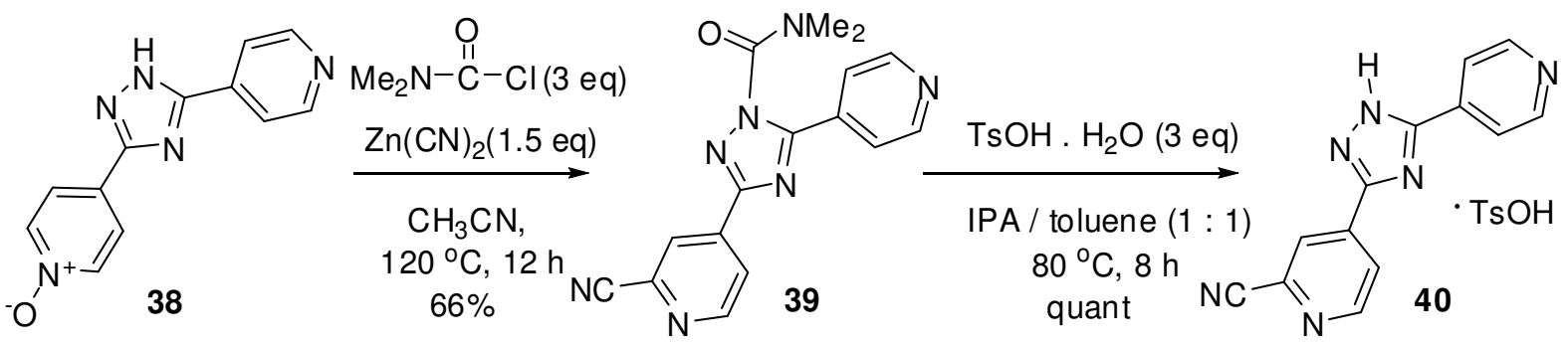

\section{Scheme 17}

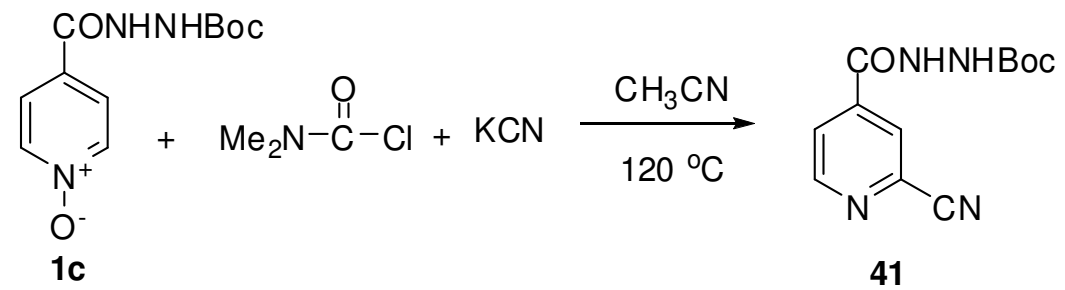

\section{Scheme 18}




\section{Transition-metal Free Regiospecific Alkylation}

Recently, Almqvist and Olsson et al. reported on the transition-metal free regiospecific synthesis of 2-substituted alkyl, alkynyl, and arylpyridines, a class of compounds prominent in medicinal chemistry and materials. Sequential addition of Grignard reagents to pyridine $N$-oxides in THF at room temperature followed by treatment of the resulting 2,4-dienal oximes $\mathbf{4 2}$ with acetic anhydride at $120{ }^{\circ} \mathrm{C}$ afforded a range of 2-substituted pyridines 43 in good to high yields (Scheme 19). ${ }^{23}$

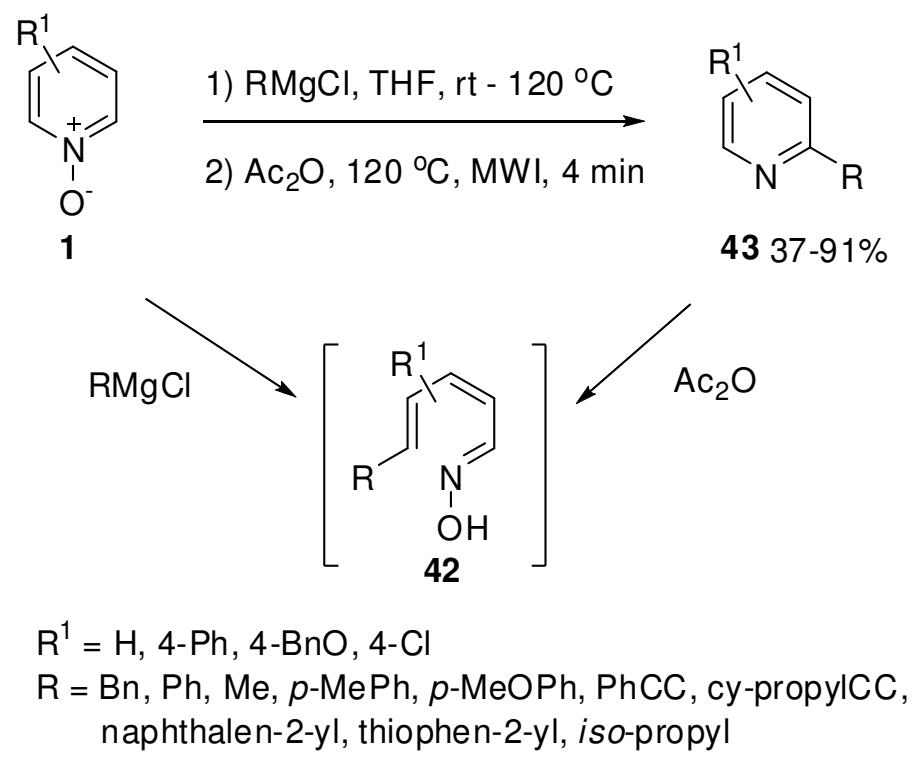

\section{Scheme 19}

Olsson and Almqvist et al. also developed a mild method for the selective 2-substitution pyridine $N$-oxides 44 via a directed ortho-metallation. Addition of $i$ - $\mathrm{PrMgCl}$ to pyridine $N$ oxides in THF at $-78{ }^{\circ} \mathrm{C}$ generated selectively an ortho-metallated species, which could be trapped with various electrophiles, ranging from aldehydes, ketones and halogens, to generate 2substituted pyridine $\mathrm{N}$-oxides (Scheme 20). ${ }^{24}$ Additionally, Duan et al. also reported similar results. 2-Bromopyridine $N$-oxides were readily magnesiated with $i$-PrMgCl $\mathrm{LiCl}$ via brominemagnesium exchange. The bromine adjacent to pyridine $N$-oxide (at 2- or 6-position) could be selectively magnesiated in the presence of halogens substituted at other positions (Scheme 21). ${ }^{25}$ 


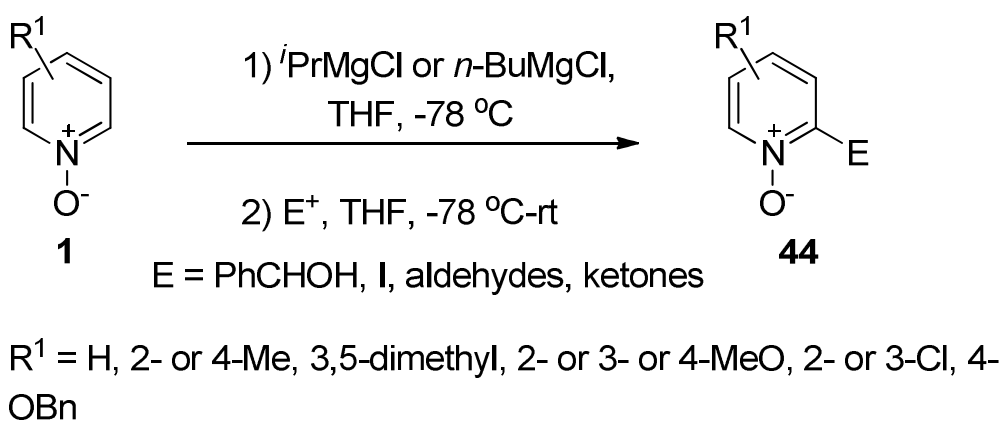

\section{Scheme 20}

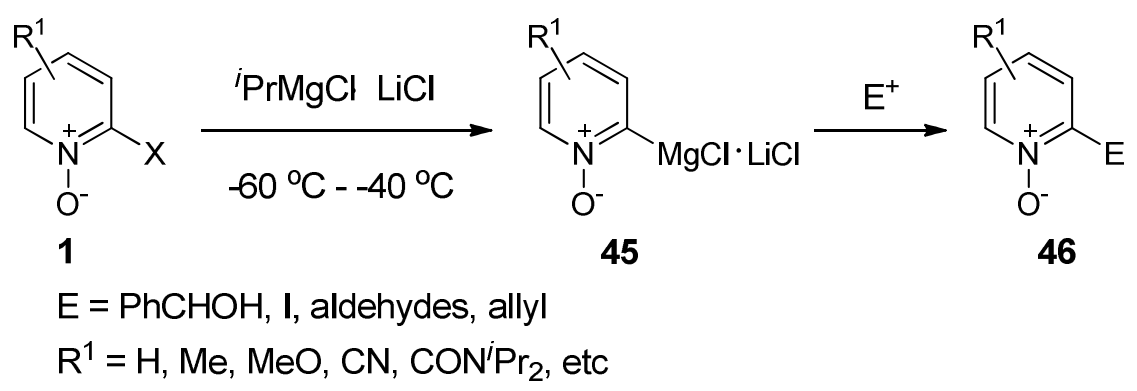

\section{Scheme 21}

Recently, Itami and Li et al. reported transition-metal-free systems for the cross-coupling reactions of nitrogen heteroaromatics and alkanes. Under the influence of $t \mathrm{BuOO} t \mathrm{Bu}$, pyridine $\mathrm{N}$-oxide derivatives reacted with alkanes to furnish the corresponding cross-coupling products (alkylated nitrogen heterocycles) in good yields. The present oxidative cross-coupling reactions at two different $\mathrm{C}-\mathrm{H}$ bonds not only contributed to the realization of "greener" synthesis, but also unlocks opportunities for markedly different strategies in chemical synthesis (Scheme 22). ${ }^{26}$

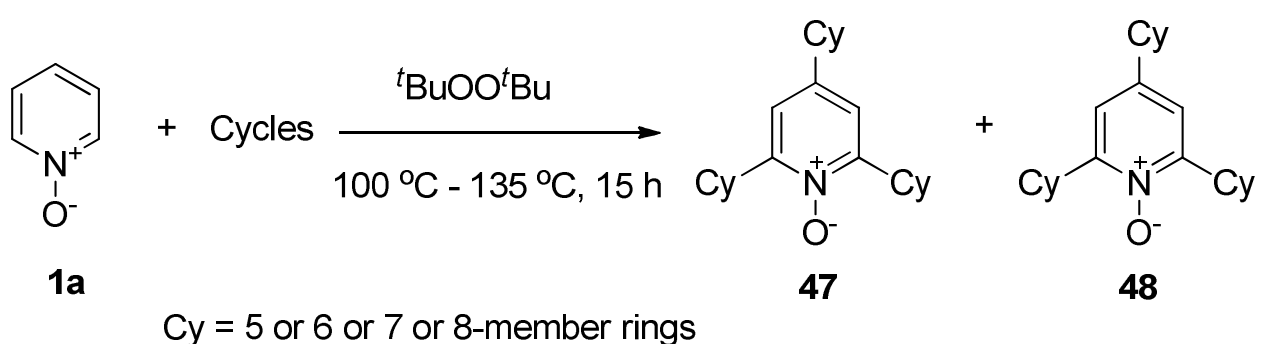

\section{Scheme 22}




\section{Transition-metal Free Alkynylation}

Chupakhin et al. reported a method for the direct introduction of acetylenes into heterocyclic systems using $\mathrm{S}_{\mathrm{N}}{ }^{\mathrm{H}}$ methodology. It provided a versatile tool for the synthesis of a series of ethynyl azines. The method requires no expensive reagents, and can be used as a complementary method to Sonogashira cross-coupling reactions (Scheme 23). ${ }^{27}$
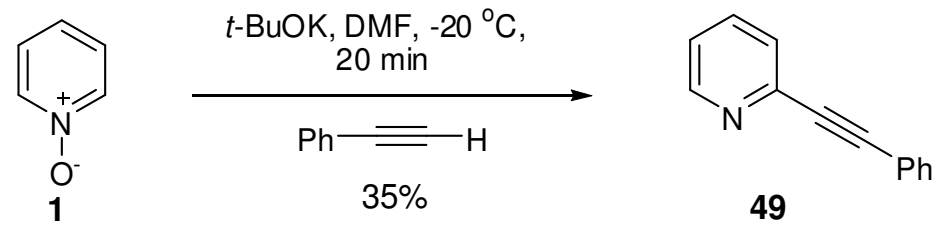

\section{Scheme 23}

\section{Palladium-catalyzed Direct (Hetero)arylation}

You, $\mathrm{Hu}$, and co-workers recently reported for the first time in $\mathrm{Pd}(\mathrm{II})$-catalyzed, copper(I)promoted oxidative cross-coupling between pyridine $\mathrm{N}$-oxides and electron-rich heteroarenes such as furans and thiophenes, where $\mathrm{Cu}(\mathrm{OAc})_{2} \mathrm{H}_{2} \mathrm{O}$ was used as an oxidant (Scheme 24). ${ }^{28}$ Plausible catalytic cycle of oxidative $\mathrm{C}-\mathrm{H} / \mathrm{C}-\mathrm{H}$ cross-coupling of heteroarenes with pyridine $\mathrm{N}$ oxides is shown in Scheme 25. In the first metalation step, the abstraction of hydrogen from thiophene took place in the reaction system. Thus, thiophene would undertake a regioselective electrophilic C-H substitution $\left(\mathrm{S}_{\mathrm{E}} \mathrm{Ar}\right)$ of $\mathrm{Pd}(\mathrm{OAc})_{2}$ to generate $\alpha$-thienylpalladium(II) intermediate 51. Then it reacted with $N$-oxide to form the key heterocoupling intermediate 52, which might be rate-determining in the entire reaction.
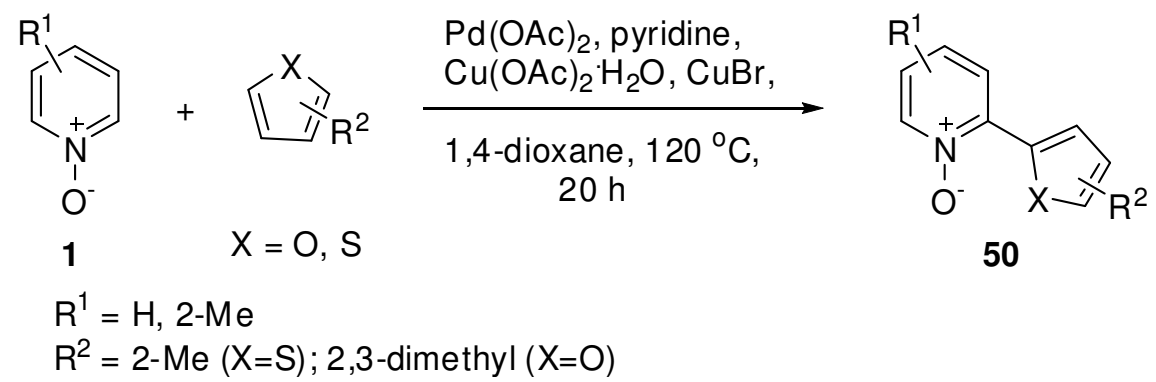

50

Scheme 24 


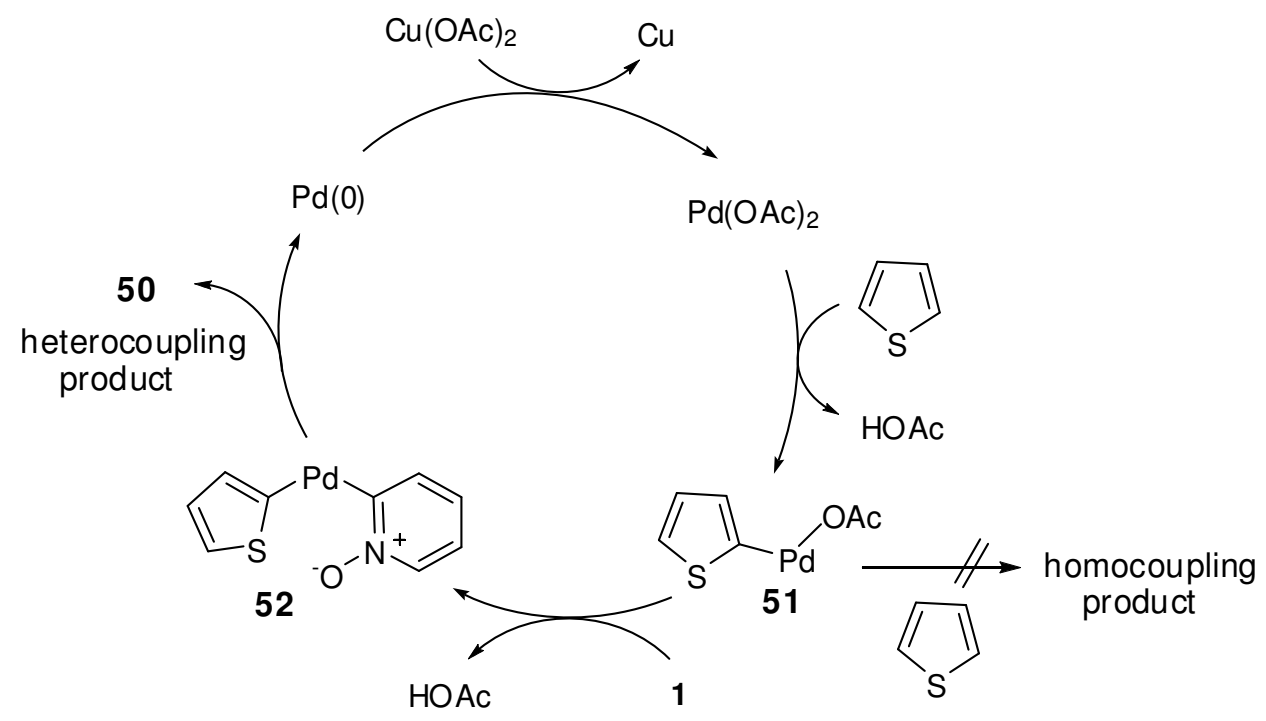

\section{Scheme 25}

Zhang, Li et al. reported a $\mathrm{Pd}(\mathrm{II})$-catalyzed oxidative coupling between pyridine $N$-oxides and $\mathrm{N}$-substituted indoles via two-fold $\mathrm{C}$-H bond activation with high selectivity using $\mathrm{Ag}_{2} \mathrm{CO}_{3}$ as an oxidant (Scheme 26). ${ }^{29}$ Recently, Yamaguchi, Itami et al. also developed similar reactions of palladium-catalyzed $\mathrm{C}-\mathrm{H} / \mathrm{C}-\mathrm{H}$ coupling reaction of indoles/ pyrroles and pyridine $\mathrm{N}$-oxides, proceeding selectively at the $\mathrm{C} 3$ position of the indoles/pyrroles and the $\mathrm{C} 2$ position of the pyridine oxides (Scheme 27). ${ }^{30}$<smiles>[O-][n+]1ccccc1</smiles>

1<smiles>[R7]n1ccc2c1CCCC2</smiles>

$\mathrm{R}^{2}$

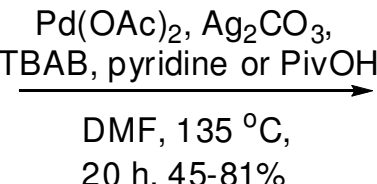

20 h, $45-81 \%$

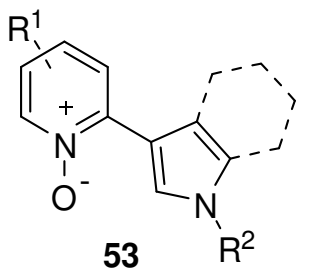

53

$\mathrm{R}^{1}=\mathrm{H}$, 2- or 4-Me, 4-tBu, 3-Ph, 3-Br, 3-CN

$\mathrm{R}^{2}=\mathrm{Bn}, \mathrm{Me}, \mathrm{Ph}$

TBAB = tetrabutylammonium bromide

\section{Scheme 26}



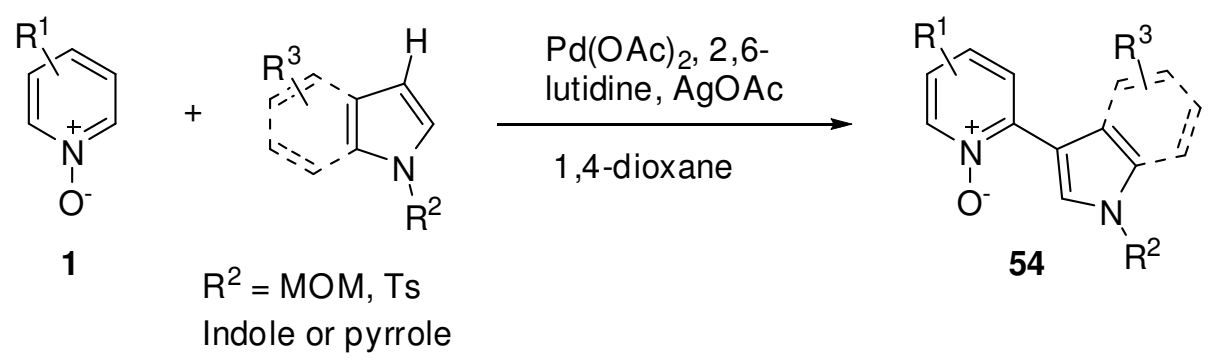

Scheme 27

\section{Conclusions}

In summary, we have described some recent advances in the synthesis of various types of 2substituted pyridines from pyridine $N$-oxides. The significance of development of synthetic methods is that it provides a useful alternative to classic approach, which has usually prepared starting from halo- or metallated pyridyl compounds. However, pyridine $N$-oxide is now being more popular because of its efficiency, and many new methods will probably be developed for the synthesis of 2-substituted pyridines in the near future.

\section{Acknowledgements}

The authors gratefully acknowledge the financial support from the Program for Professor of Special Appointment (Eastern Scholar) at Shanghai Institutions of Higher Learning (No ZXDF160002). The Project-sponsored by SRF for ROCS, SEM.

\section{References}

1. (a) Scriven, E. F. V. In Comprehensive Heterocyclic Chemistry, Part 2; Boulton, A. J., McKillop, A., Eds.; Pergamon: New York, 1984; Vol. 2, pp 165-314. http://dx.doi.org/10.1016/B978-008096519-2.00027-8.

(b) Hilton. S.; Naud, S.; Caldwell, J.; Boxall, K.; Burns, S.; Anderson, V. E.; Antoni, L.; Allen, C. E.; Pearl, L. H.; Oliver, A. W.; Aherne, G. W.; Garrett, M. D.; Collins, I. Bioorg. Med. Chem. 2010, 707-718.

http://dx.doi.org/10.1016/j.bmc.2009.11.058 PMid:20022510. 
2. (a) Dzierszinski, F.; Coppin, A.; Mortuaire, M.; Dewally, E.; Slomianny, C.; Ameisen, J.-C.; Debels, F.; Tomavo, S. Antimicrob. Agents. Chemother. 2002, 46, 3197-3207. http://dx.doi.org/10.1128/AAC.46.10.3197-3207.2002 PMid:12234845 PMCid:128807.

(b) Kletsas, D.; Li, W.; Han, Z.; Papadopoulos, V. Biochem. Pharmacol. 2004, 67, 19271930. http://dx.doi.org/10.1016/j.bcp.2004.01.021 PMid:15130769.

(c) Mach, U. R.; Hackling, A. E.; Perachon, S.; Ferry, S.; Wermuth, C. G.; Schwartz, J.-C.; Sokoloff, P.; Stark, H. ChemBioChem 2004, 5, 508-518. http://dx.doi.org/10.1002/cbic.200300784 PMid:15185375.

(d) Muscarella, D. E.; O'Brian, K. A.; Lemley, A. T.; Bloom, S. E. Toxicol. Sci. 2003, 74, 6673. http://dx.doi.org/10.1093/toxsci/kfg052 PMid:12730627

3. (a) Murray, R. W.; Jeyaraman, R. J. Org. Chem. 1985, 50, 2847-2853.

http://dx.doi.org/10.1021/jo00216a007.

(b) Albini, A.; Pietra, S. Heterocyclic N-oxides CRC Press: Boca Raton, 1991. PMCid:1535627.

(c) Albini, A. Synthesis 1993, 263.

http://dx.doi.org/10.1055/s-1993-25843.

(d) Youssif, S. Arkivoc 2001 (i) 242-268.

(e) Chelucci, G.; Thummel, R. P. Chem. Rev. 2002, 102, 3129-3170.

http://dx.doi.org/10.1021/cr0101914 PMid:12222984.

(f) van den Heuval, M.; van den Berg, T. A.; Kellogg, R. M.; Choma, C. T.; Feringa, B. L. J. Org. Chem. 2004, 69, 250-262.

http://dx.doi.org/10.1021/jo035157z PMid:14725436.

(g) Ito, R.; Umezawa, N.; Higuchi, T. J. Am. Chem. Soc. 2005, 127, 824-825.

http://dx.doi.org/10.1021/ja045266a PMid:15656606

4. (a) Ochiai, E. Aromatic Amine Oxides, Elsevier: Amsterdam, 1967. http://dx.doi.org/10.1021/jo00796a004

(b) Kobayashi, Y.; Kumadaki, I.; Sato, H. J. Org. Chem. 1972, 37, 3588-3591.

5. Cho, S. H.; Hwang, S. J.; Chang, S. J. Am. Chem. Soc. 2008, 130, 9254-9256. http://dx.doi.org/10.1021/ja8026295 PMid:18582040

6. Wu, J.; Cui, X.; Chen, L.; Jiang, G.; Wu, Y. J. Am. Chem. Soc. 2009, 131, 13888-13889. http://dx.doi.org/10.1021/ja902762a PMid:19746974

7. Kanyiva, K. S.; Nakao, Y.; Hiyama, T. Angew. Chem. Int. Ed. 2007, 46, 8872-8874. http://dx.doi.org/10.1002/anie.200703758 PMid:17990254

8. Campeau, L-C.; Stuart, D. R.; Leclerc, J-P.; Bertrand-Laperle, M.; Villemure, E.; Sun, H-Y.; Lasserre, S.; Guimond, N.; Lecavallier, M.; Fagnou, K. J. Am. Chem. Soc. 2009, 131, 32913306. http://dx.doi.org/10.1021/ja808332k PMid:19215128

9. Huestis, M. P.; Fagnou, K. Org. Lett. 2009, 11, 1357-1360.

http://dx.doi.org/10.1021/o1900150u PMid:19226145 
10. Leclerc, J-P.; Fagnou, K. Angew. Chem. Int. Ed. 2006, 45, 7781-7786. http://dx.doi.org/10.1002/anie.200602773 PMid:17061301

11. Campeau, L-C.; Rousseaux, S.; Fagnou, K. J. Am. Chem. Soc. 2005, 127, 18020-18021. http://dx.doi.org/10.1021/ja056800x PMid:16366550

12. Campeau, L-C.; Schipper, D. J.; Fagnou, K. J. Am. Chem. Soc. 2008, 130, 3266-3267. http://dx.doi.org/10.1021/ja710451s PMid:18293986

13. Lapointe, D.; Markiewicz, T.; Whipp, C. J.; Toderian, A.; Fagnou, K. J. Org. Chem. 2011, 76, 749-759. http://dx.doi.org/10.1021/jo102081a PMid:21117710

14. Schipper, D. J.; EI-Salfiti, M.; Whipp, C. J.; Fagnou, K. Tetrahedron 2009, 65, 4977-4983. http://dx.doi.org/10.1016/j.tet.2009.03.077

15. Yin, J. J.; Xiang, B. P.; Huffman, M. A.; Raab, C. E.; Davies, I. W. J. Org. Chem. 2007, 72, 4554-4557. http://dx.doi.org/10.1021/jo070189y PMid:17500567

16. Londregan, A. T.; Jennings, S.; Wei, L. Org. Lett. 2010, 12, 5254-5257. http://dx.doi.org/10.1021/ol102301u PMid:20958085

17. Londregan, A. T.; Jennings, S.; Wei, L. Org. Lett. 2011, 13, 1840-1843. http://dx.doi.org/10.1021/ol200352g PMid:21375291

18. Manley, P. J.; Bilodeau, M. T. Org. Lett. 2002, 4, 3127-3129. http://dx.doi.org/10.1021/o10264556 PMid:12201733

19. Keith, J. M. J. Org. Chem. 2008, 73, 327-330. http://dx.doi.org/10.1021/jo702038g PMid:18067315

20. Keith, J. M. J. Org. Chem. 2010, 75, 2722-2725. http://dx.doi.org/10.1021/jo1001017 PMid:20297806

21. Huo, Z. B.; Kosugi, T.; Yamamoto, Y. Tetrahedron Lett. 2008, 49, 4369-4371. http://dx.doi.org/10.1016/j.tetlet.2008.05.029

22. Huo, Z. B.; Kosugi, T.; Yamamoto, Y. Acta. Chim. Slov. 2009, 56, 659-663.

23. Andersson, H.; Almqvist, F.; Olsson, R. Org. Lett. 2007, 9, 1335-1337. http://dx.doi.org/10.1021/o1070184n PMid:17328555

24. Andersson, H.; Gustafsson, M.; Olsson, R.; Almqvist, F. Tetrahedron Lett. 2008, 49, 69016903. http://dx.doi.org/10.1016/j.tetlet.2008.09.104

25. Duan, X-F.; Ma, Z-Q.; Zhang, F.; Zhang, Z-B. J. Org. Chem. 2009, 74, 939-942. http://dx.doi.org/10.1021/jo802172f PMid:19055346

26. Deng, G.; Ueda, K.; Yanagisawa, S.; Itami, K.; Li, C-J. Chem. Eur. J. 2009, 15, 333-337. http://dx.doi.org/10.1002/chem.200801893 Mid:19035592

27. Prokhorov, A. M.; Makosza, M.; Chupakhin, O. N. Tetrahedron Lett. 2009, 50, 1444-1446. http://dx.doi.org/10.1016/j.tetlet.2009.01.070

28. Xi, P.; Yang, F.; Qin, S.; Zhao, D.; Lan, J.; Gao, G.; Hu, C.; You, J. J. Am. Chem. Soc. 2010, 132, 1822-1824. http://dx.doi.org/10.1021/ja909807f PMid:20102197

29. Gong, X.; Song, G.; Zhang, H.; Li, X. Org. Lett. 2011, 13, 1766-1769. http://dx.doi.org/10.1021/ol200306y PMid:21388218 
30. Yamaguchi, A.; Mandal, D.; Yamaguchi, J.; Itami, K. Chem. Lett. 2011, 40, 555-557. http://dx.doi.org/10.1246/cl.2011.555

\section{Authors' Biographies}

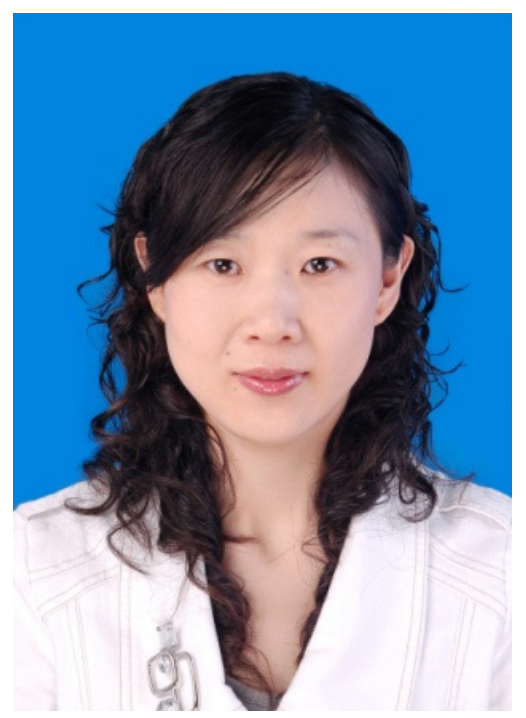

Chunli Liu received her BS from the Southwest University, China, in 1999 .Since 1999, she worked in Guizhou Normal University. From 2007 to 2008, she worked in Prof. Yoshinori Yamamoto's group as an invited scholar at Tohoku University, Japan. She received her MS in organic chemistry from Guizhou University in 2009. Since 2009, she worked as an associate professor in Guizhou Normal University. Her current research interests include photocatalytic oxidative degradation of organic pollutants and selective photooxidation for the synthesis of organic chemicals. 


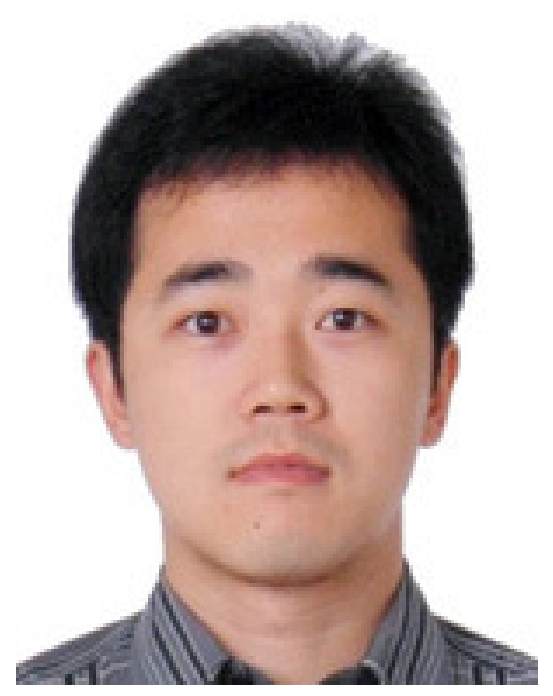

Jiang Luo was born in 1986 in Shandong, China. He received his B. S., M. S. in materials physics and chemistry from Central South University and Graduate University of Chinese Academy of Science respectively. He is currently a Ph.D student of the School of Environmental Science and Engineering, Shanghai Jiao Tong University, China, under the guidance of Prof. Zhibao Huo. His research interests include transition metal- and Lewis acid-mediated development of new synthetic methods.

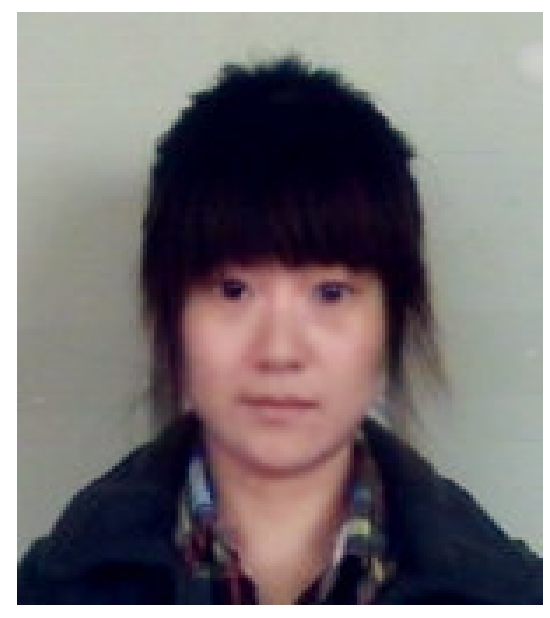

Lingli Xu was born in 1988 in Lanzhou, China. She received her B. S. in Environmental Science and Engineering from Jiang Shu university and she is currently a master student of the School of Environmental Science and Engineering, Shanghai Jiao Tong University, China, under the guidance of Prof. Zhibao Huo. Her research interests include transition metal- and Lewis acidmediated development of new synthetic methods, asymmetric catalysis. 


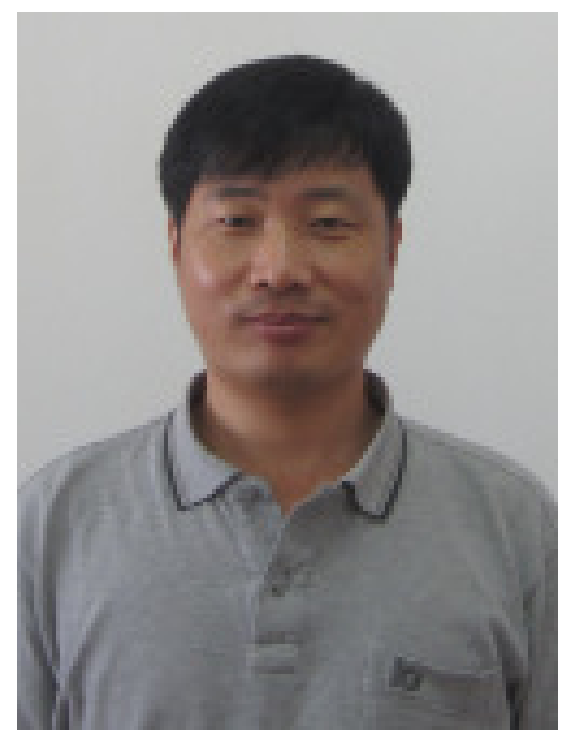

Zhibao Huo was born in Shenyang, China, in 1971. He completed his master and doctoral studies at Tohoku University in 2004 and 2007 under the guidance of Prof. Yoshinori Yamamoto. After working for about three years as a postdoctoral fellow in the same laboratory, in April 2010, he was appointed as Professor of Organic Chemistry at Shanghai Jiao Tong University, China. His research interests include transition metal- and Lewis acid-mediated development of new synthetic methods, asymmetric catalysis, and synthesis of biologically important natural and unnatural compounds. 